Supporting Information

\title{
Growth of $\mathrm{Cu}$ Nanobelt and Ag Belt Like Materials by Surfactant Assisted Galvanic Reductions
}

Ting-Kai Huang, Tzu-Hou Cheng, Ming-Yu Yen, Wei-Han Hsiao, Lung-Shen Wang, Fu-Rong Chen, Ji-Jung Kai, Chi-Young Lee and Hsin-Tien Chiu* 


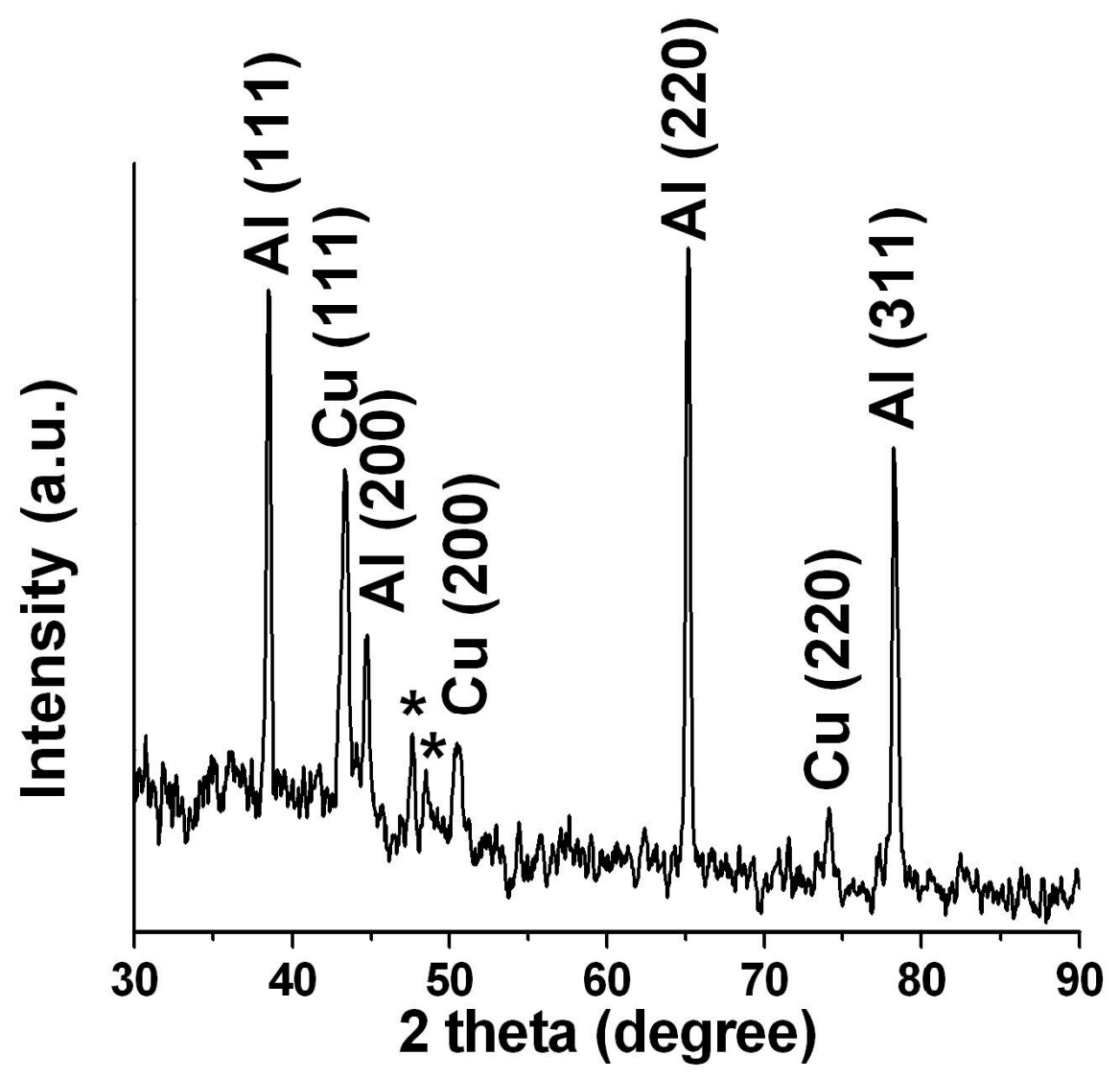

Figure S1. XRD pattern of $\mathrm{Cu}$ nanobelts grown on an $\mathrm{Al}$ grid $(*=$ unknown) 


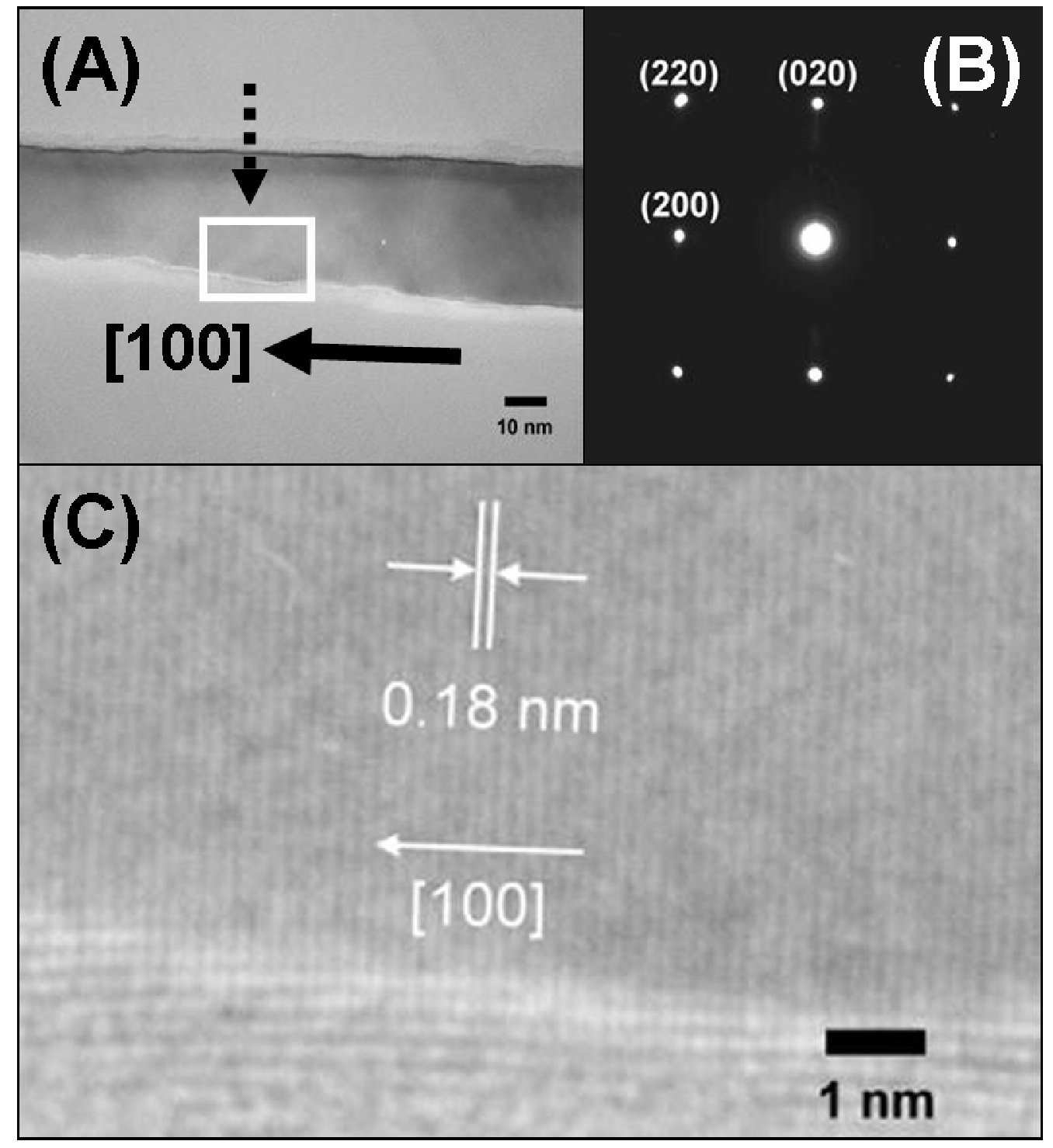

Figure S2. (A) TEM image of a $\mathrm{Cu}$ nanobelt showing $[1,0,0]$ projected growth direction, (B) $[0,0,1]$ zone SAED, and (C) HRTEM image of the marked rectangular region pointed by a dotted arrow in (A). 


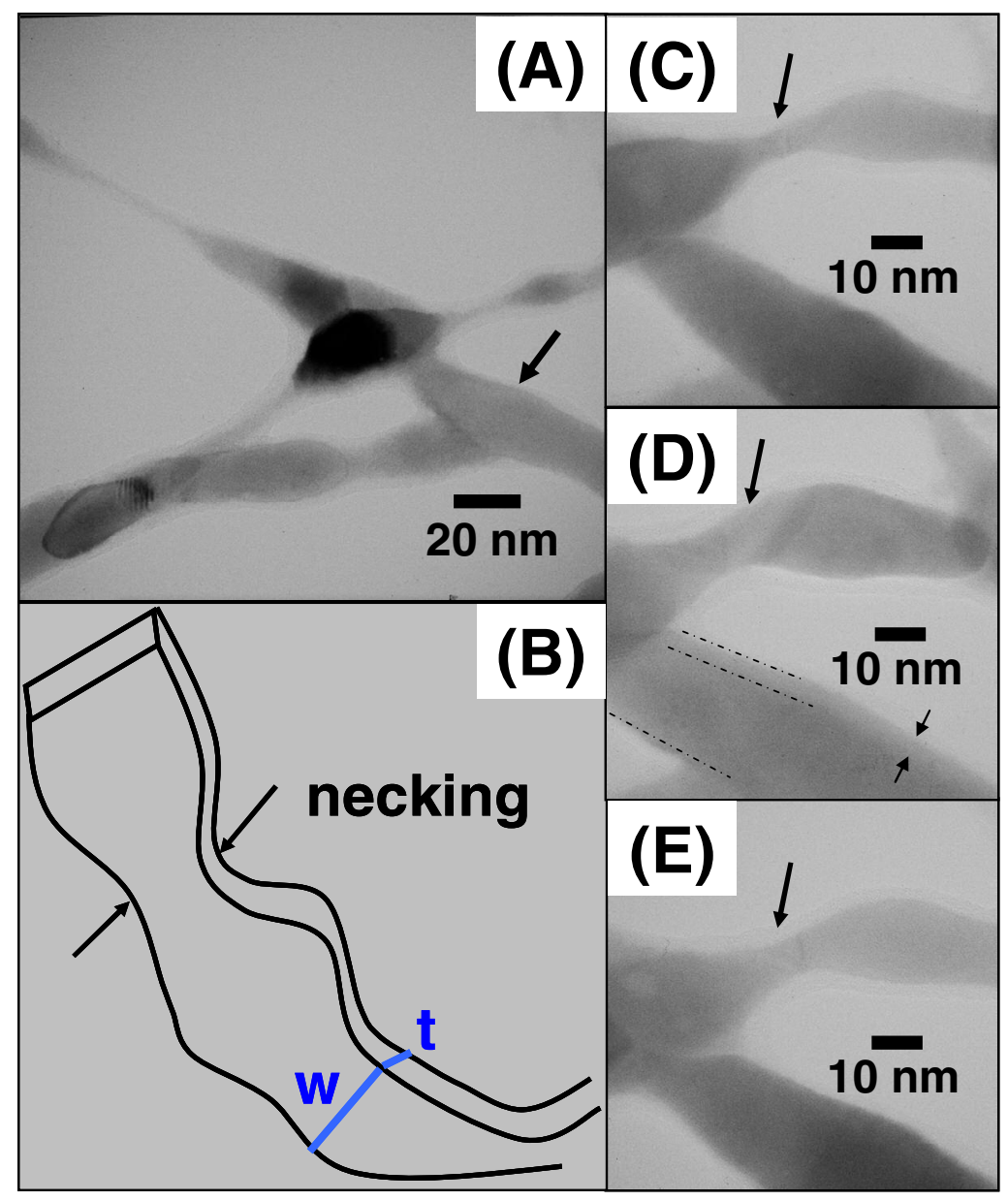

Figure S3. (A) TEM image and (B) cartoon scheme of belt-like Ag. Enlarged TEM views from the region marked by an arrow in (A): (C) at original sample stage position $(\mathrm{x}=0, \mathrm{y}=0),(\mathrm{D})$ after tilting $\mathrm{y}$ axis of the sample stage by 19 degrees $(\mathrm{x}=$ $0, y=19)$, and $(E)$ after tilting $\mathrm{x}$ axis of the sample stage by 19 degrees $(\mathrm{x}=19, \mathrm{y}=$ 0). The images (C) - (E) show that the belt-like Ag has a variable width, which can be seen clearly at the point marked by an arrow. The image (D) suggests that the products have a thickness of $4 \mathrm{~nm}$. A variable width $11-23 \mathrm{~nm}$ can be observed in (A). This corresponds to a w/t aspect ratio $3-6$. 

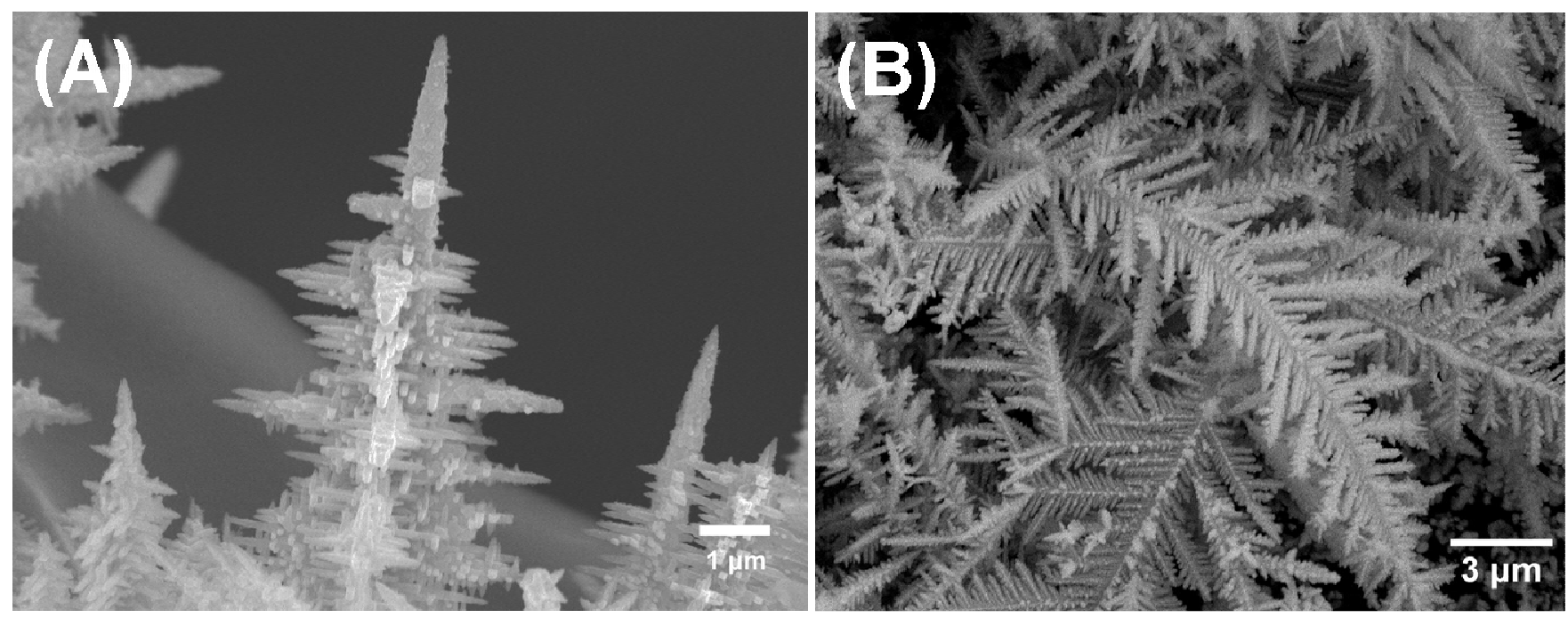

Figure S4. SEM images of (A) Cu dendrites grown on an Al grid and (B) Ag dendrites grown on a $\mathrm{Cu}$ grid without adding CTAC. 


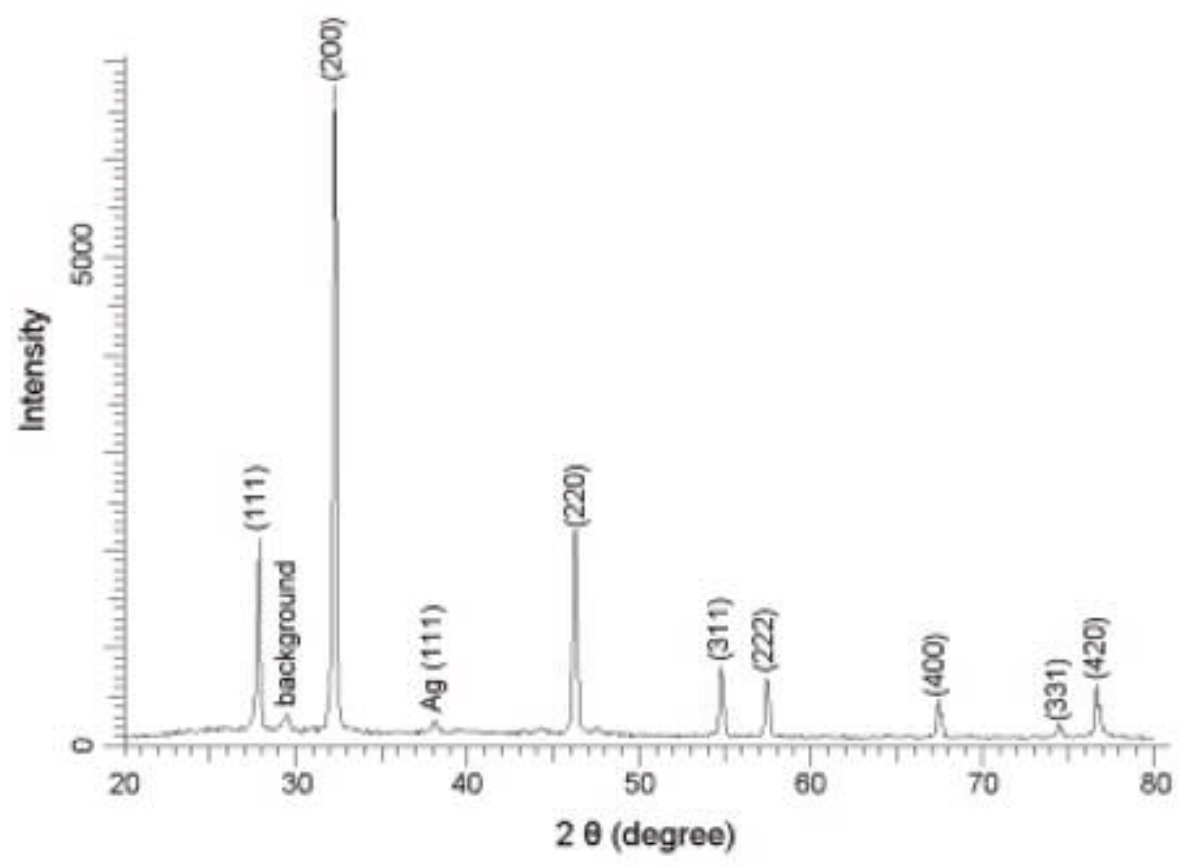

Figure S5. XRD pattern of $\mathrm{AgCl}$ formed from mixing $\mathrm{AgNO}_{3}$ solution with CTAC. 


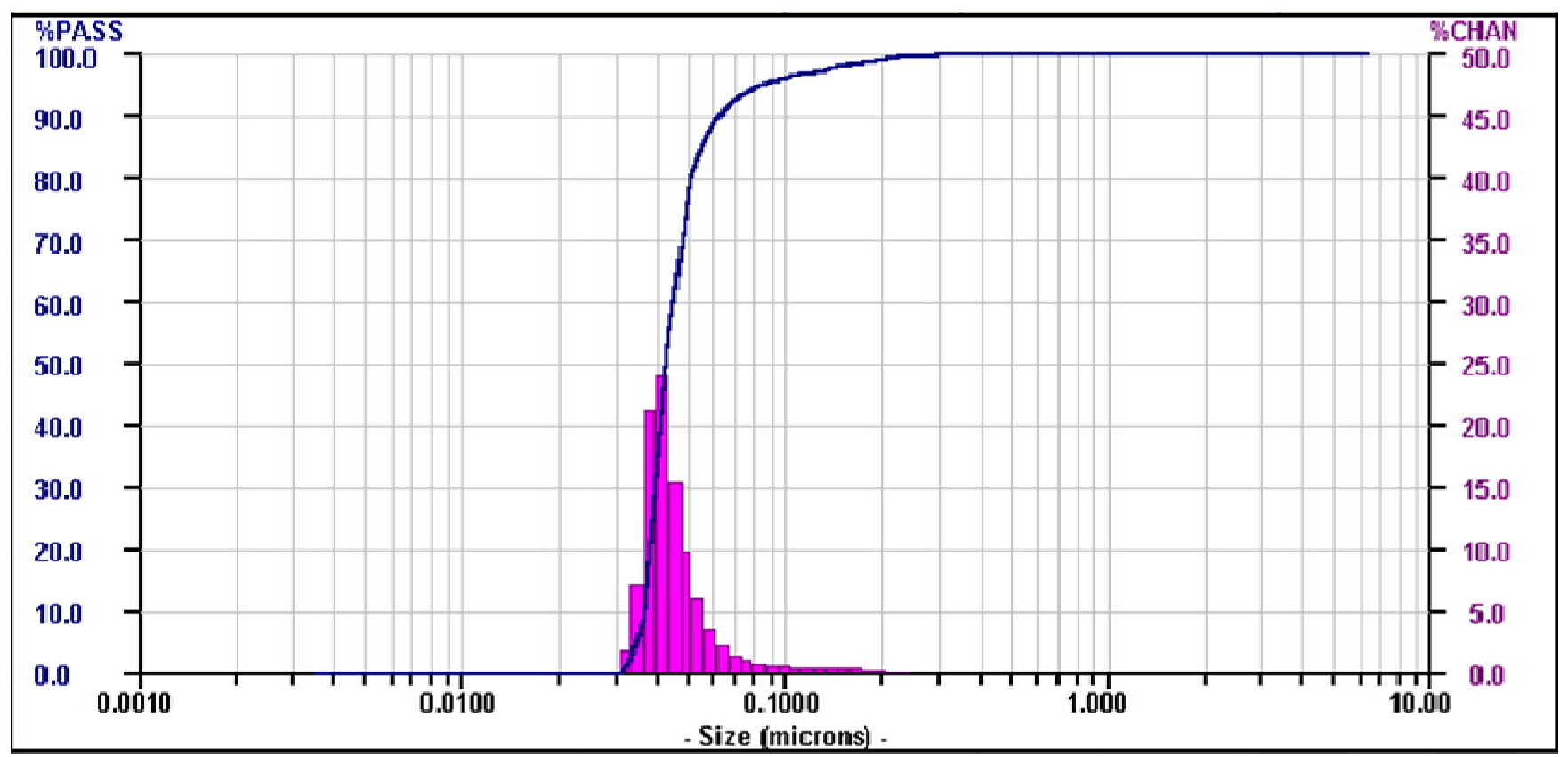

Figure S6. Particle size distribution of $\mathrm{AgCl}$ formed from mixing $\mathrm{AgNO}_{3}$ solution with $\mathrm{CTAC}$. The light scattering experiment used single-beam and the following parameters. $\mathrm{AgCl}$, reflectivity: 2.07; density: $5.56 \mathrm{gm} / \mathrm{cc}$. Deionized water (solvent): reflectivity: 1.33; viscosity: 0.797 (303 K) - 1.002 (293 K). Standard deviation is $8.3 \mathrm{~nm}$. Dielectric is not required. 


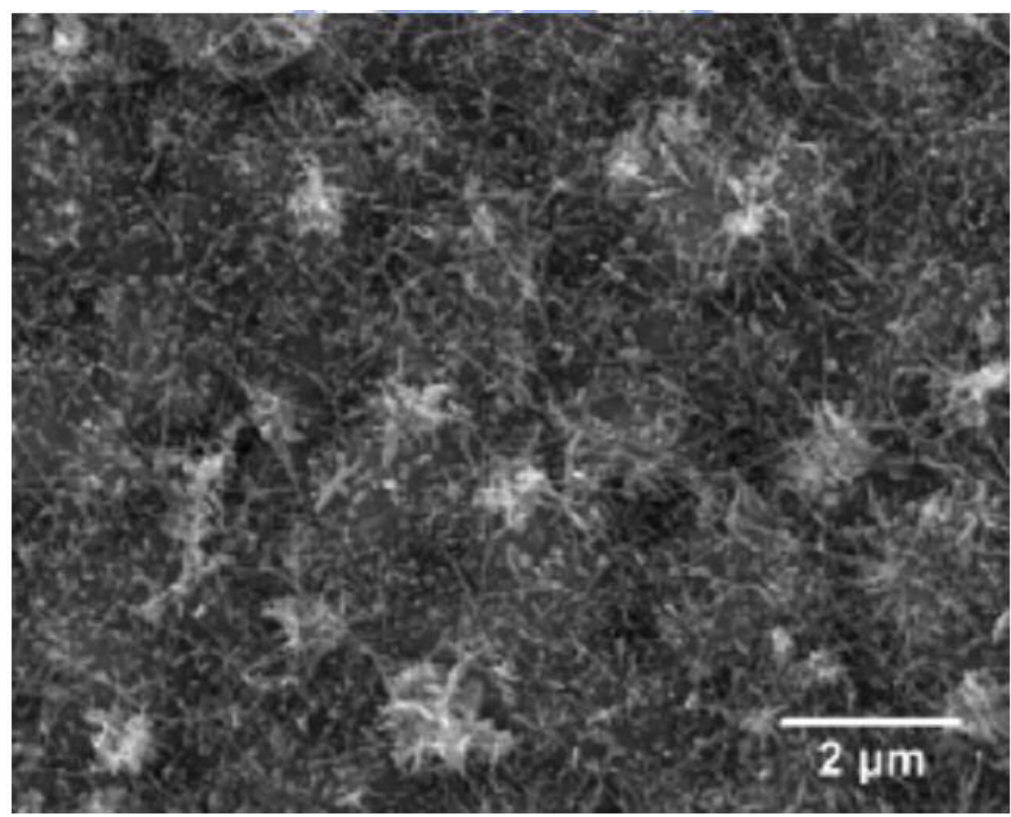

Figure S7. SEM image of $\mathrm{Ag}$ grown on a $\mathrm{Cu}$ grid. The $\mathrm{CTAC} / \mathrm{AgNO}_{3}$ solution was mixed in darkness. 


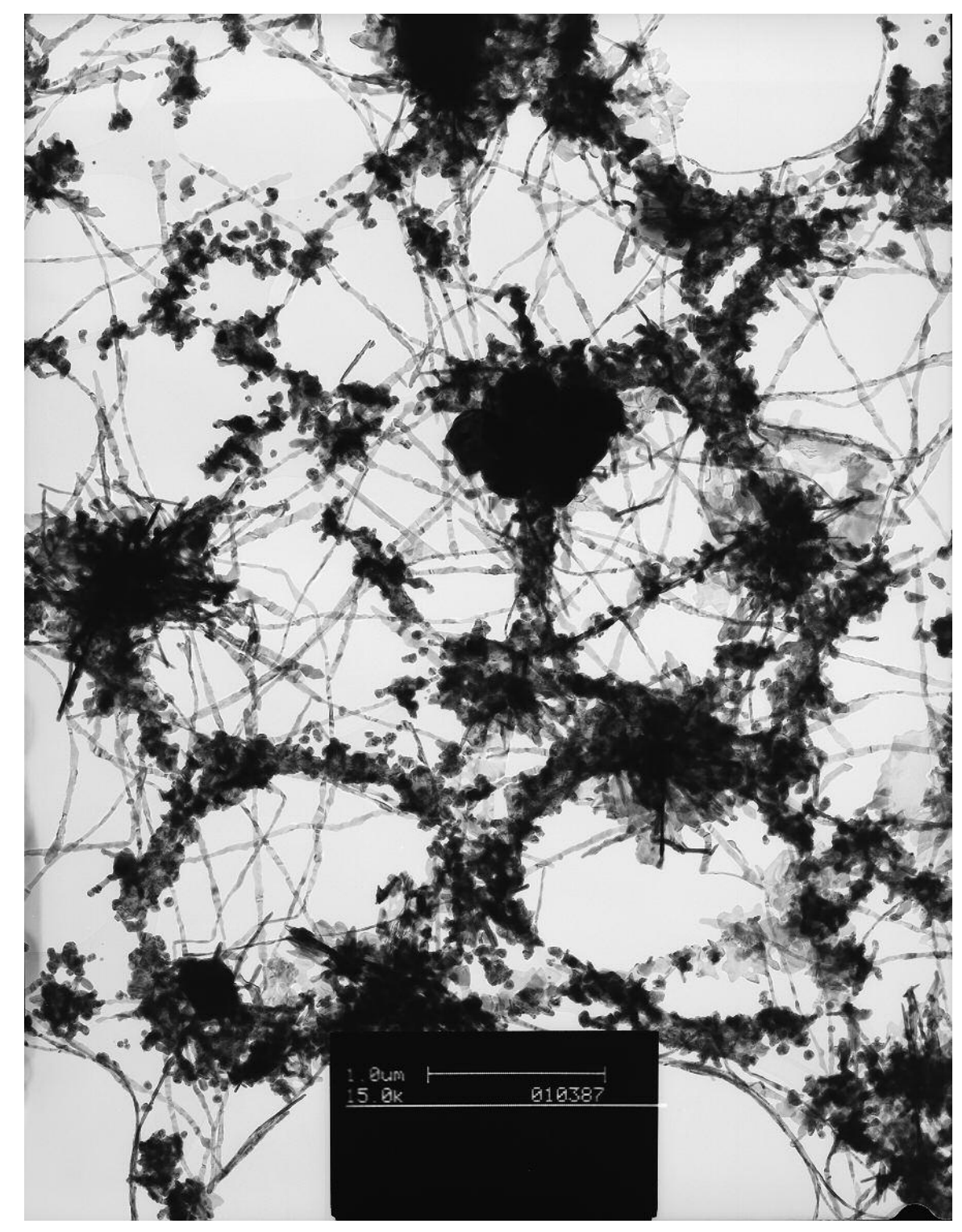

Figure S8. TEM image of $\mathrm{Ag}$ grown on a $\mathrm{Cu}$ grid with the $\mathrm{CTAC} / \mathrm{AgNO}_{3}$ mixture stirred for $5 \mathrm{~m}$ and stand for $5 \mathrm{~m}$ before the grid was immersed. 


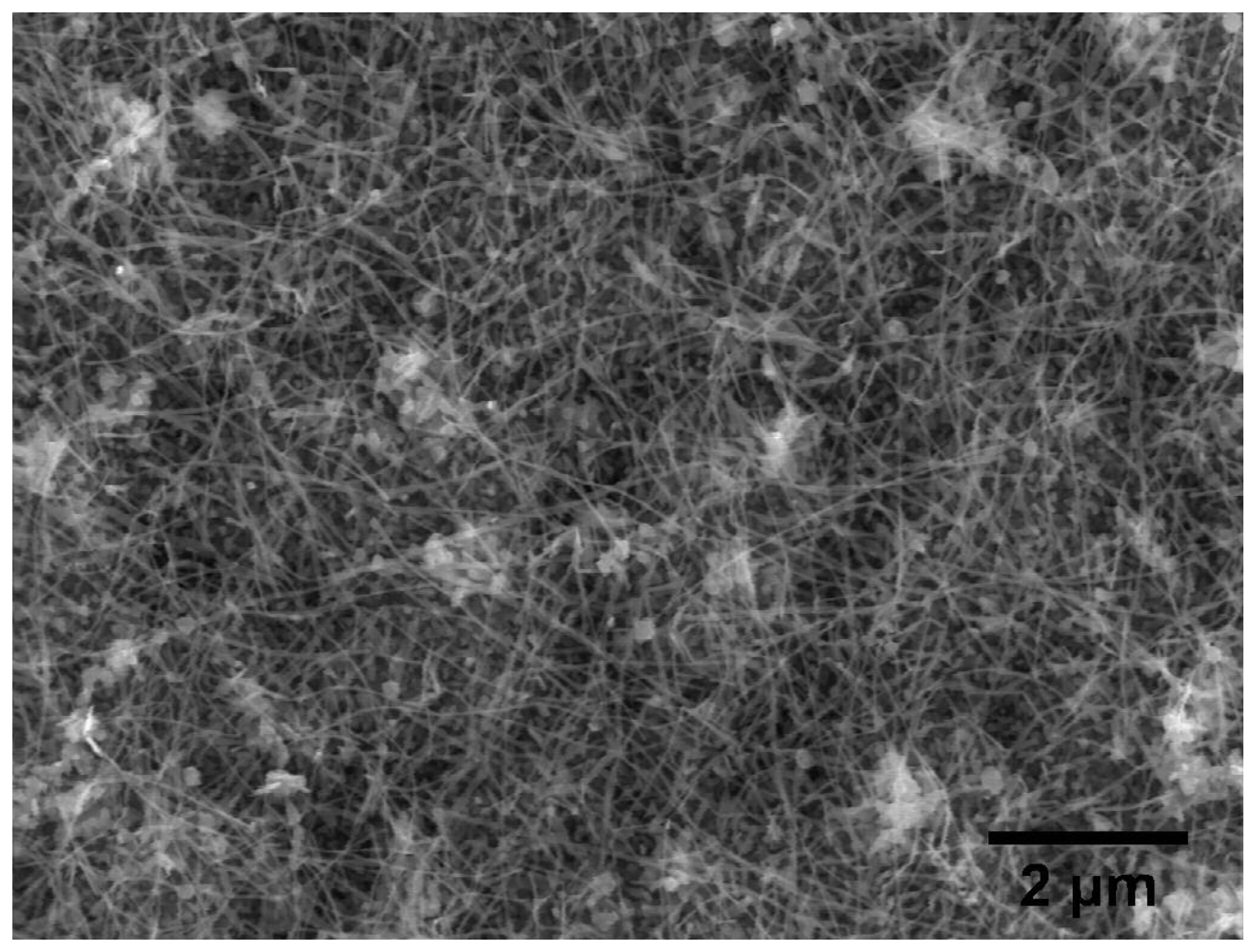

Figure S9. SEM image of $\mathrm{Ag}$ grown on a $\mathrm{Cu}$ grid with the $\mathrm{CTAC} / \mathrm{AgNO}_{3}$ mixture stirred for $25 \mathrm{~m}$ and stand for $5 \mathrm{~m}$ before the grid was immersed. 


$$
\frac{1}{d^{2}}=\frac{4}{3}\left(\frac{h^{2}+h k+k^{2}}{a^{2}}\right)+\frac{l^{2}}{c^{2}}
$$

\begin{tabular}{|l|l|l|l|}
\hline \multicolumn{4}{|l|}{ Lattice Parameters } \\
\hline JCPDS & \multicolumn{2}{l|}{ Calculated from XRD } \\
NO. 87-0598 & \multicolumn{3}{l|}{} \\
\hline$a=0.2886 \mathrm{~nm}$ & $a=0.288 \mathrm{~nm}$ & $a=0.296 \mathrm{~nm}$ & $a=0.288 \mathrm{~nm}$ \\
\hline$c=1.0 \mathrm{~nm}$ & $c=1.13 \mathrm{~nm}$ & $c=0.998 \mathrm{~nm}$ & $c=0.998 \mathrm{~nm}$ \\
\hline
\end{tabular}

Table S1. Using the equation above, lattice constants are estimated from the XRD pattern in Fig. 6 by assuming that the peak at $36.0^{\circ}$ is a combination of $4 \mathrm{H} \operatorname{Ag}(1,0,-1,0)$ and $4 \mathrm{H} \operatorname{Ag}(0,0,0,4)$, and the peak at $39.5^{\circ}$ is $4 \mathrm{H} \operatorname{Ag}(1,0,-1,2)$. Three sets of possible lattice parameter data are estimated and listed in the table. The values are averaged to give $a=0.291 \mathrm{~nm}$ and $c=1.04 \mathrm{~nm}$. These are close to the reported value of $4 \mathrm{H} \mathrm{Ag}, a=0.2886 \mathrm{~nm}$ and $c=1.0 \mathrm{~nm}$. 